\title{
Controlled Synthesis of Gold Nanobelts and Nanocombs in Aqueous Mixed Surfactant Solutions
}

Nana Zhao, Yang Wei, Nijuan Sun, Qian Chen, Jingwei Bai, Longping Zhou, Yao Qin, Meixian Li, and Limin Qi*

Beijing National Laboratory for Molecular Sciences (BNLMS), State Key Laboratory for Structural Chemistry of Unstable and Stable Species, College of Chemistry, Peking University, Beijing 100871, P.R. China.E-mail: liminqi@pku.edu.cn

\section{Supporting Information}

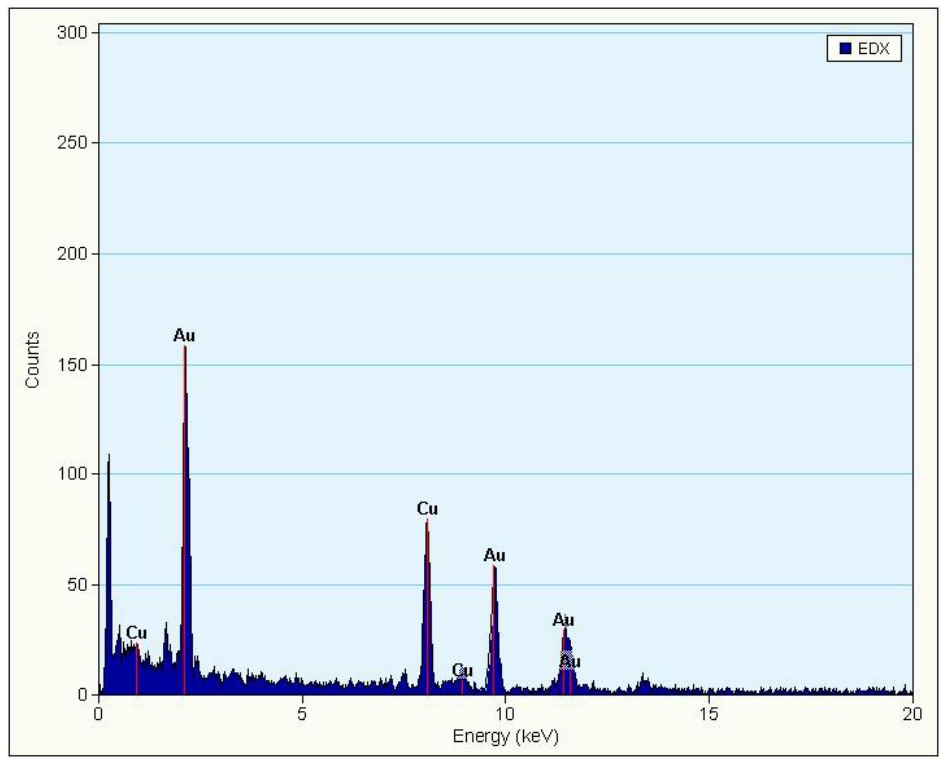

Figure S1. EDS spectrum of gold nanobelts obtained at $4^{\circ} \mathrm{C}$. 

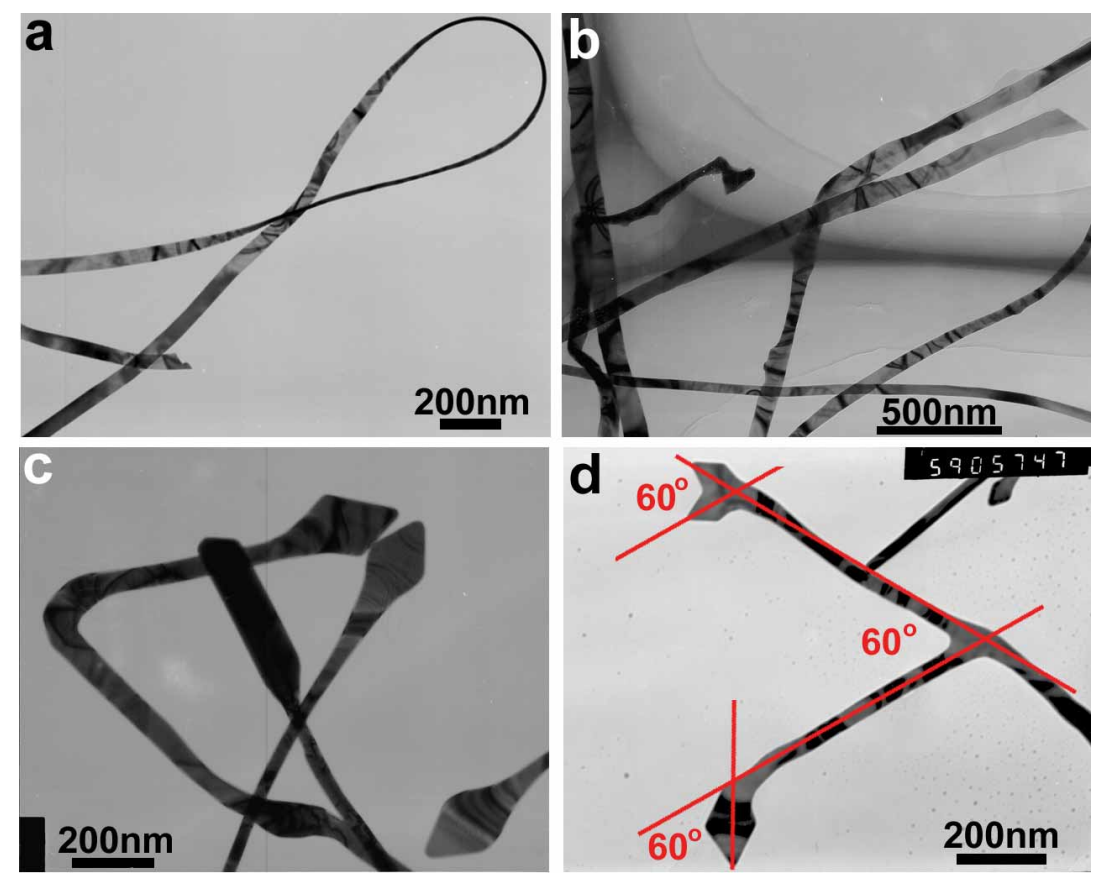

Figure S2. TEM images of gold nanobelts obtained at $4{ }^{\circ} \mathrm{C}(\mathrm{a}, \mathrm{b})$ and $27^{\circ} \mathrm{C}(\mathrm{c}, \mathrm{d})$ showing the ends of the nanobelts.
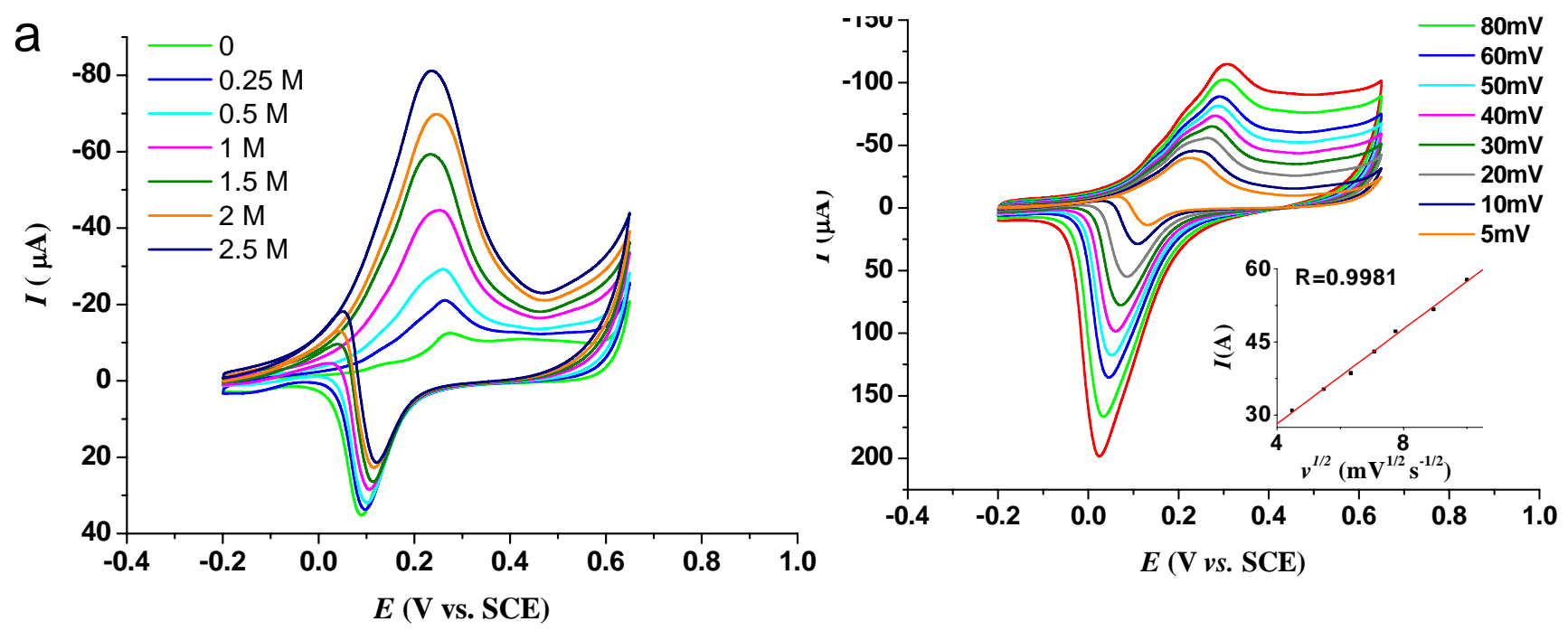

Figure S3. (a) Cyclic voltammograms for the oxidation of methanol on $27^{\circ} \mathrm{C}$ gold nanobelts electrode in $0.1 \mathrm{M} \mathrm{KOH}$ at different methanol concentrations. Scan rate: $10 \mathrm{mV} / \mathrm{s}$. (b) Cyclic voltammograms for the oxidation of methanol $(1 \mathrm{M})$ on $27^{\circ} \mathrm{C}$ gold nanobelts electrode in $0.1 \mathrm{M} \mathrm{KOH}$, Inset shows the corresponding plot of peak current against square root of scan rate. 

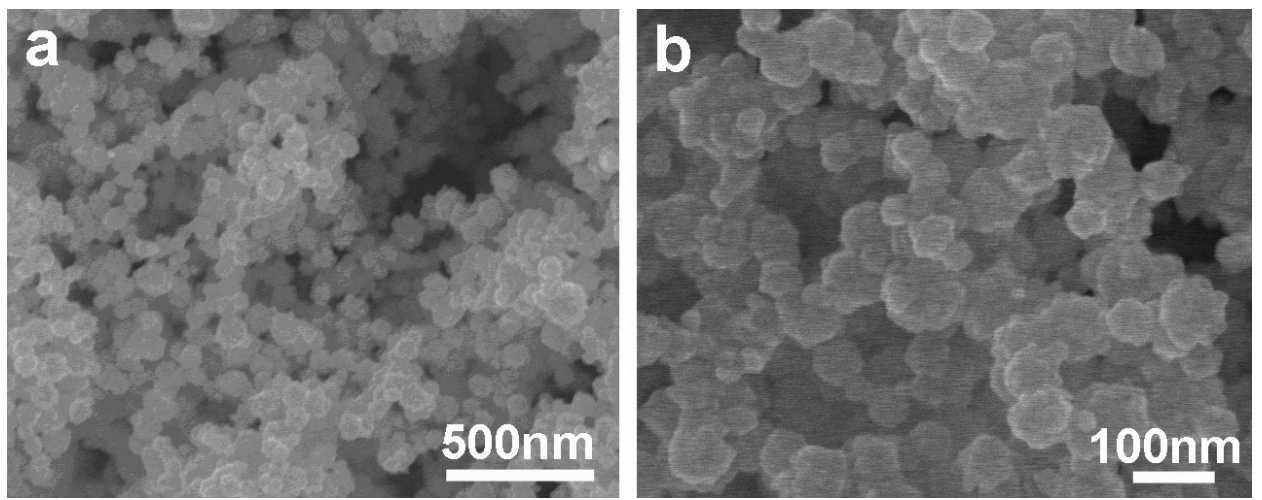

Figure S4. SEM images of $~ 50 \mathrm{~nm}$ gold nanoparticles used as reference sample for the SERS measurement. 